\title{
Highly specialized suspension-feeding bony fish Rhinconichthys (Actinopterygii: Pachycormiformes) from the mid-Cretaceous of the United States, England, and Japan
}

\author{
Bruce A. Schumacher ${ }^{\text {a, b, * }}$, Kenshu Shimada ${ }^{c, d}$, Jeff Liston ${ }^{\text {e, f, g, h }}$, Anthony Maltese ${ }^{\mathrm{i}}$ \\ a USDA Forest Service, La Junta, CO 81050, USA \\ ${ }^{\mathrm{b}}$ Denver Museum of Nature and Science, Denver, CO 80205, USA \\ ${ }^{c}$ Department of Environmental Science and Studies and Department of Biological Sciences, DePaul University, 2325 North Clifton Avenue, \\ Chicago, IL 60614, USA \\ ${ }^{\mathrm{d}}$ Sternberg Museum of Natural History, Fort Hays State University, Hays, KS 67601, USA \\ e Yunnan Key Laboratory for Palaeobiology, Yunnan University, Kunming 650091, Yunnan Province, People's Republic of China \\ f Department of Natural Sciences, National Museum of Scotland, Old Town, Edinburgh, Chambers Street, Edinburgh, EH1 1JF, Scotland, UK \\ ${ }^{\mathrm{g}}$ School of Earth Sciences, University of Bristol, Wills Memorial Building, Queen's Road, Bristol, BS8 1RJ, England, UK \\ ${ }^{\mathrm{h}}$ Institute of Biodiversity, Animal Health and Comparative Medicine, College of Medical, Veterinary and Life Sciences, University of Glasgow, University \\ Avenue, Glasgow, G12 8QQ Scotland, UK \\ ${ }^{i}$ Rocky Mountain Dinosaur Resource Center, Woodland Park, CO 80863, USA
}

\section{A R T I C L E I N F O}

\section{Article history:}

Received 22 September 2015

Received in revised form

15 December 2015

Accepted in revised form 28 December 2015

Available online $\mathrm{xxx}$

\section{Keywords:}

Cenomanian

Osteichthyes

Pachycormid

Phylogeny

Planktivory

Turonian

\begin{abstract}
A B S T R A C T
We re-define the Cretaceous bony fish genus Rhinconichthys by re-describing the type species, $R$. taylori, and defining two new species, $R$. purgatorensis sp. nov. from the lowermost Carlile Shale (middle Turonian), southeastern Colorado, United States; and $R$. uyenoi sp. nov. from the Upper Cretaceous (Cenomanian) Mikasa Formation, Middle Yezo Group, Hokkaido, Japan. Rhinconichthys purgatoirensis sp. nov. is designated on a newly discovered specimen consisting of a nearly complete skull with pectoral elements. Only known previously by two Cenomanian age specimens from England and Japan, the North American specimen significantly extends the geographic and stratigraphic range of Rhinconichthys. The skull of Rhinconichthys is elongate, including an expansive gill basket, and estimated maximum body length ranges between 2.0 and $2.7 \mathrm{~m}$. Rhinconichthys was likely an obligate suspension-feeder due to its derived cranial morphology, characterized by a remarkably large and elongate hyomandibula. The hyomandibula mechanically acts as a lever to thrust the jaw articulation and hyoid arch both ventrally and anterolaterally during protraction, thus creating a massive buccal space to maximize filtering of planktonic prey items. Cladistic analysis supports a monophyly of suspension-feeding pachycormids including Rhinconichthys, but further resolution within this clade will require more information through additional fossil specimens.
\end{abstract}

Published by Elsevier Ltd.

\section{Introduction}

Suspension feeding is a specialized prey capture strategy whereby many aquatic vertebrates evolve an oral apparatus suited for planktivory (Liston, 2013). Some modern representatives include the whale shark (Rhincodontidae), basking shark (Cetorhinidae), megamouth shark (Megachasmidae), and manta rays (Mobulidae) as well as baleen whales (Mysticeti) and the

\footnotetext{
* Corresponding author. USDA Forest Service, La Junta, CO 81050, USA.

E-mail address: baschumacher@fs.fed.us (B.A. Schumacher).
}

freshwater paddlefish (Polyodon) (Lazzaro, 1987; Sanderson and Wassersug, 1993; Friedman, 2012). These modern taxa emerged during the Cenozoic, although several examples of pre-Cenozoic suspension-feeding vertebrates are known including $<0.5-\mathrm{m}$-long early Permian acanthodians (Liston, 2013) and putative Cretaceous elasmobranchs (Shimada et al., 2015). The most prominent extinct lineage of suspension-feeding vertebrates is a Middle-Late Jurassic pachycormid bony fish clade including modest sized taxa such as 2+-m-long Martillichthys (Liston, 2008) and Asthenocormus (Woodward, 1895) as well as Leedsichthys that possibly ranged up to $16.5 \mathrm{~m}$ in length (Liston et al., 2013). Recently, Cretaceous suspension-feeding pachycormids were made known (Friedman 
et al., 2010) with descriptions of Bonnerichthys from North America and Rhinconichthys from western Europe and Japan.

During field work in 2012, one of the authors (BAS) noted a concretion protruding from marl beds of Greenhorn Limestone on the Comanche National Grassland in southeastern Colorado, United States (Fig. 1A, B). Sampling the concretion with a rock hammer serendipitously revealed fin rays of a bony fish, leading to an initial field identification of pachycormid, possibly the billfish-like genus Protosphyraena (Stewart, 1988; Kear, 2007).

Further excavation revealed a flattened spheroid concretion roughly $45 \mathrm{~cm}$ in maximum dimension, capped by a delicate layer of fossil bone (Fig. 1C). Subsequent preparation revealed a nearly complete skull with pectoral girdles and the proximal portions of pectoral fins (Figs. 2-5). The unsegmented, bifurcating pectoral fin rays confirm the specimen's identity as a member of the family Pachycormidae (Lambers, 1992). The edentulous jaws reveal a vastly different form than the carnivorous Protosphyraena, and the specimen was ultimately determined to be Rhinconichthys.

Rhinconichthys is known from only two other partial skulls of Cenomanian age from England and Japan. Herein, we review the ancestry of Rhinconichthys, and describe a novel skull construction and highly specialized jaw mechanics for the genus. The new
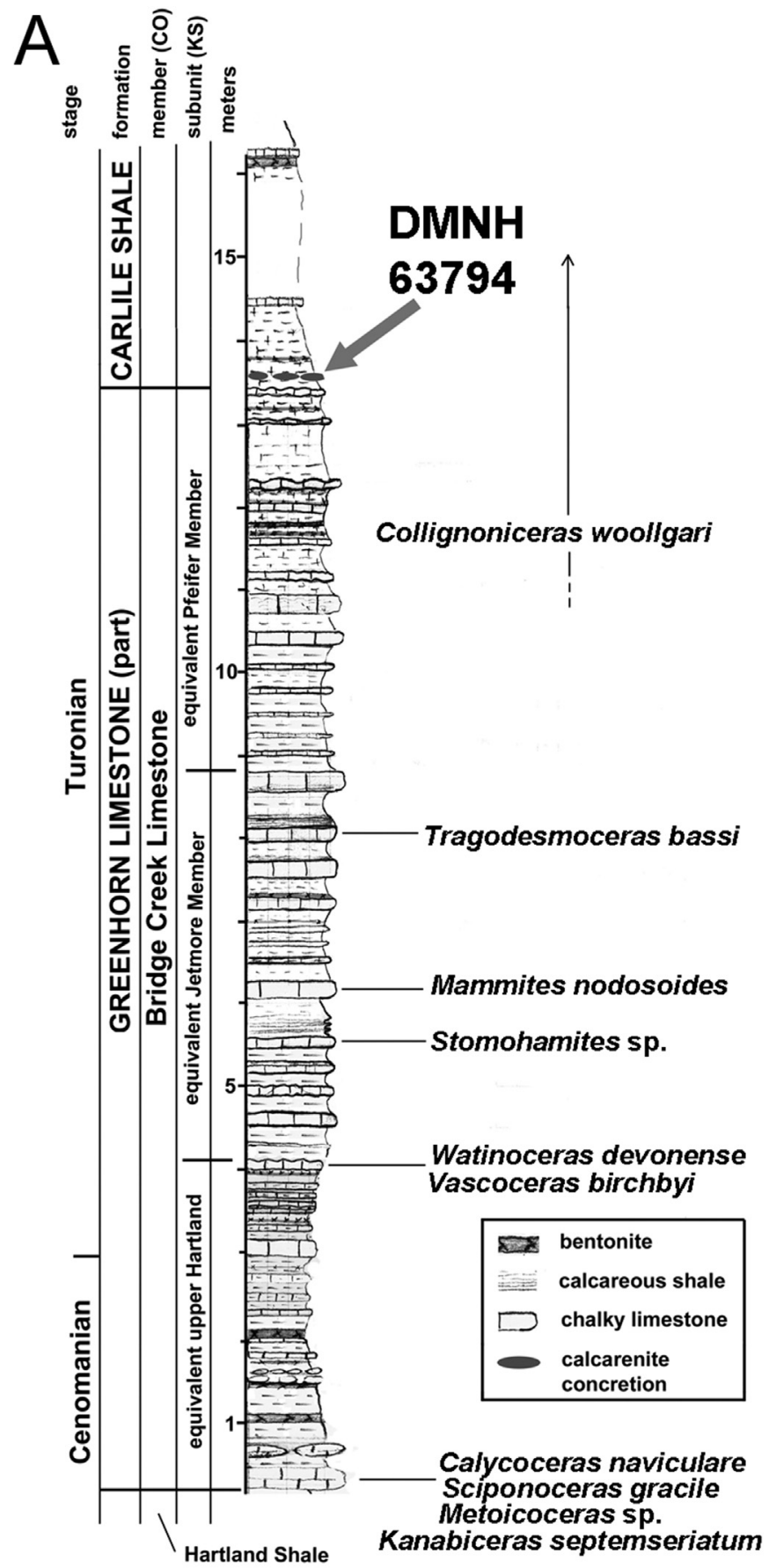
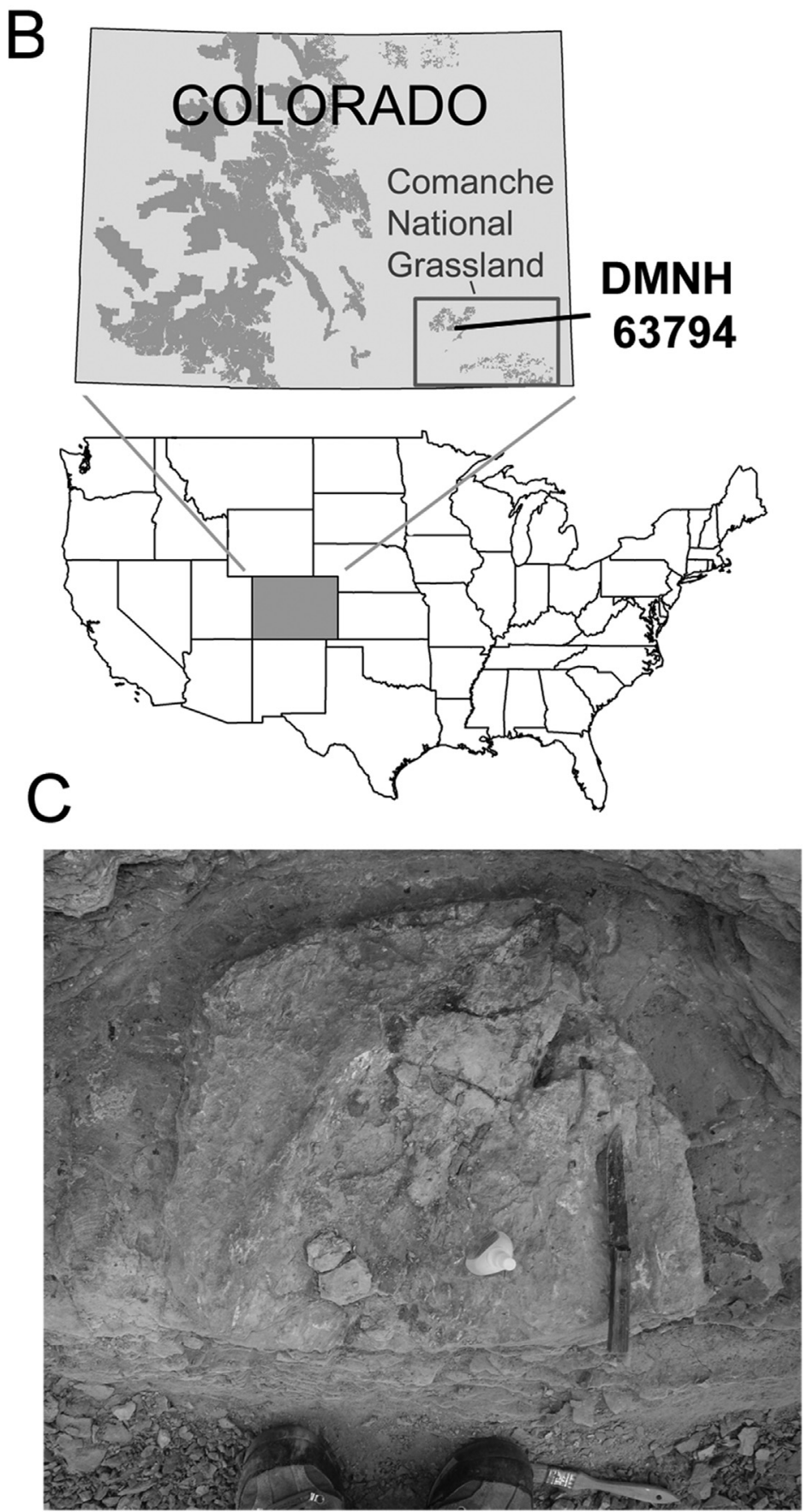

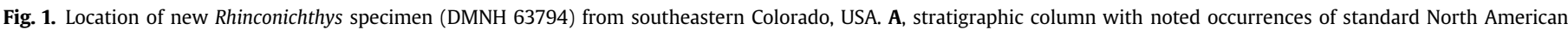
ammonites and DMNH 63794; B, map of USA showing DMNH 63794 locality; C, DMNH 63794 as exposed in field, 19-cm-long knife as scale. 


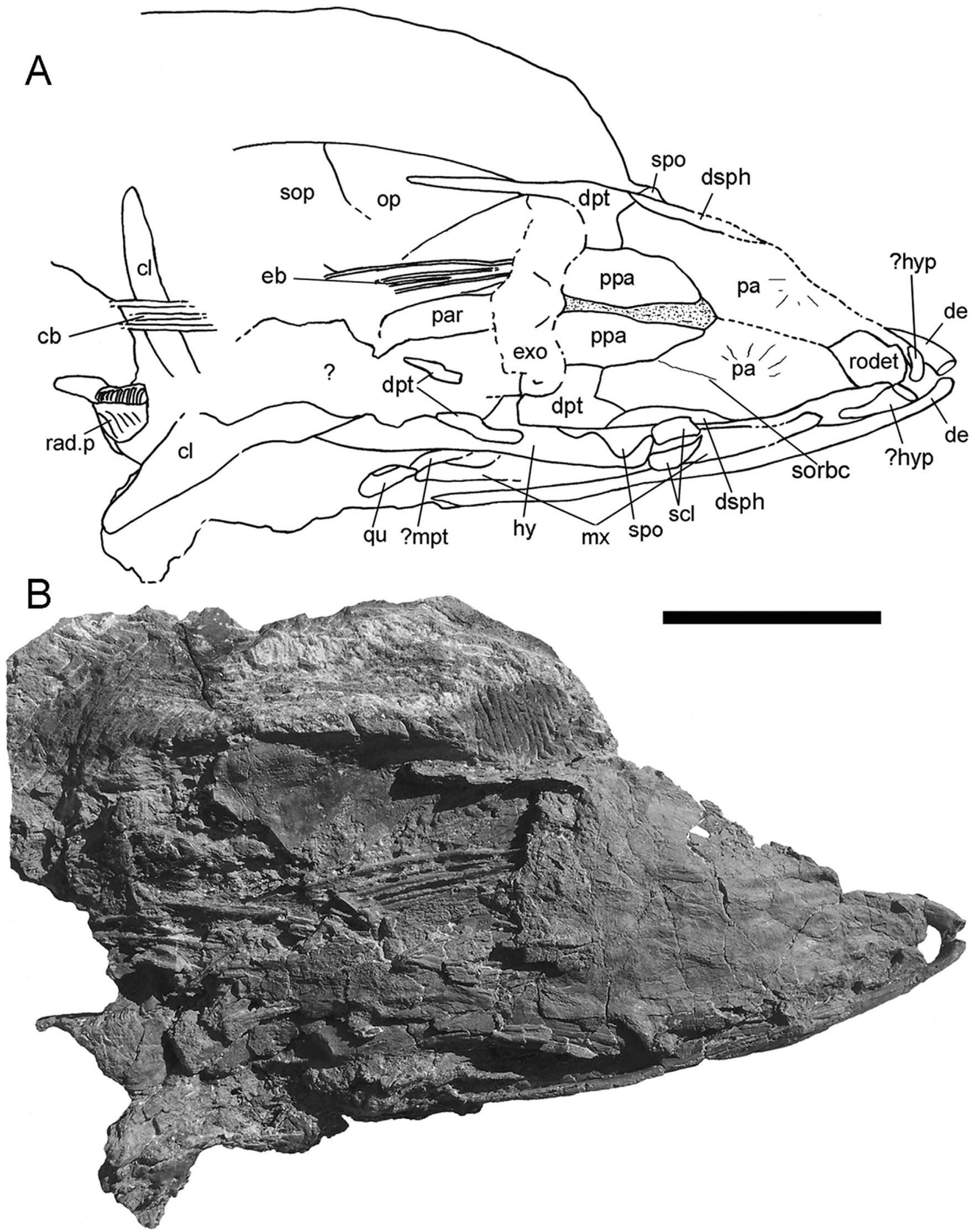

Fig. 2. Skull of Rhinconichthys purgatoirensis sp. nov. (DMNH 63794: holotype) in dorsal view. A, interpretative line drawing; $\mathbf{B}$, photograph. $\mathrm{Scale}$ bar $=10 \mathrm{~cm}$. 


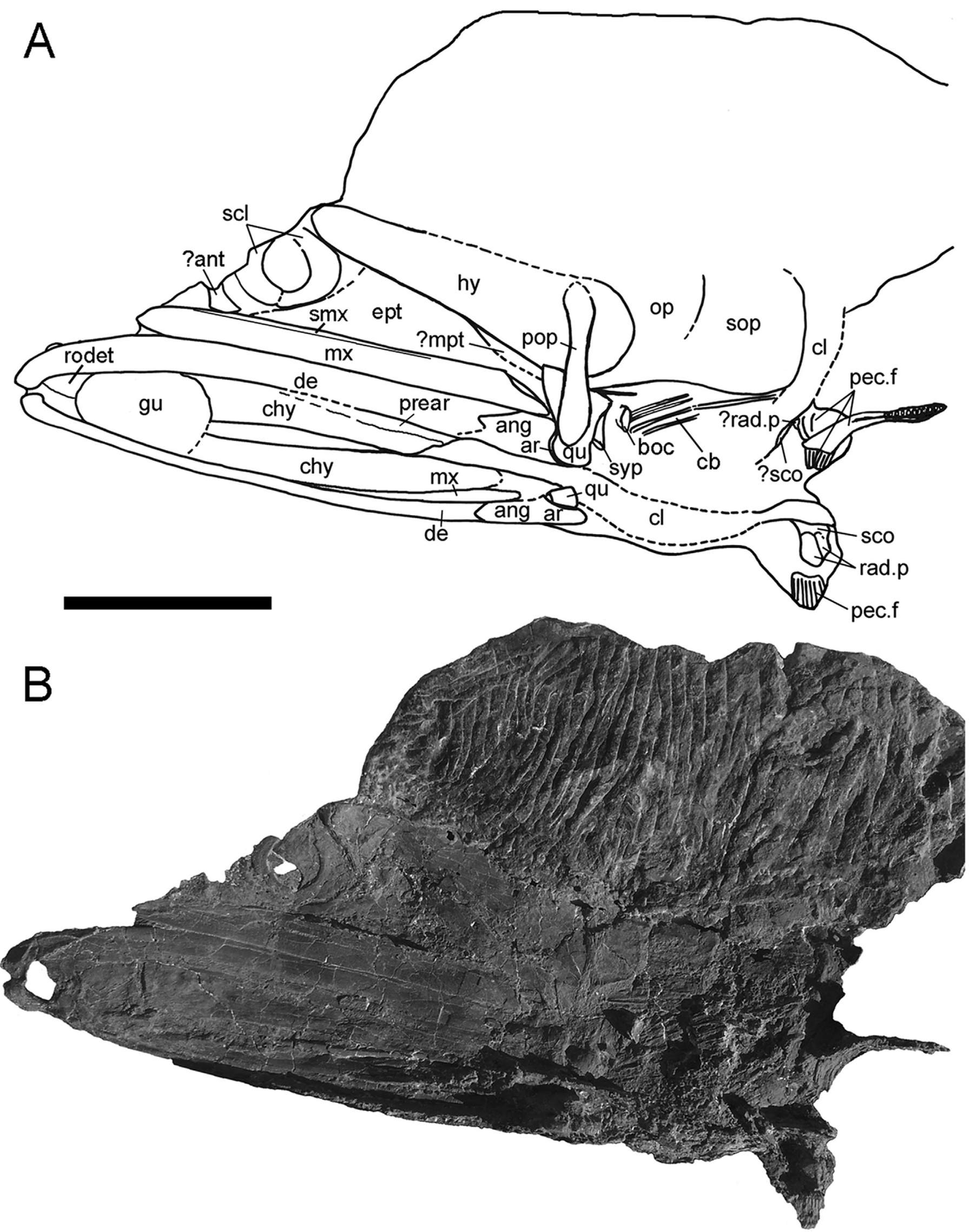

Fig. 3. Skull of Rhinconichthys purgatoirensis sp. nov. (DMNH 63794: holotype) in ventrolateral view. A, interpretive line drawing; $\mathbf{B}$, photograph. Scale bar $=10 \mathrm{~cm}$. 


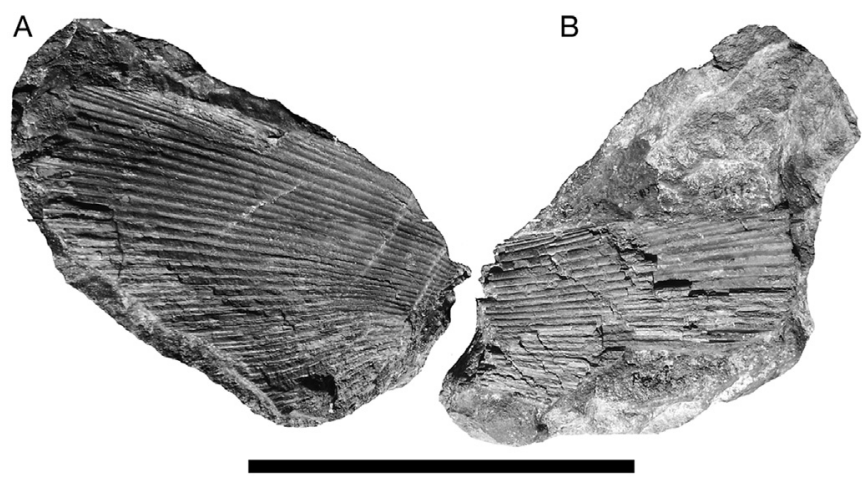

Fig. 4. Proximal portion of right pectoral fin (dorsal surface; anterior at top) of Rhinconichthys purgatoirensis sp. nov. (DMNH 63794: holotype). A, counterpart (proximal to right); B, part (proximal to left). Scale bar $=10 \mathrm{~cm}$.

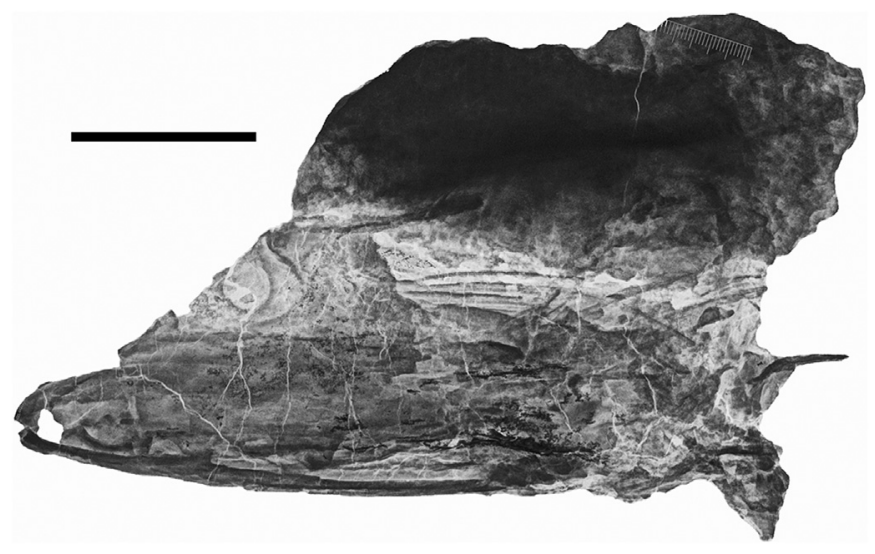

Fig. 5. X-ray image of skull of Rhinconichthys purgatoirensis sp. nov. (DMNH 63794: holotype) revealing thin, elongate epibranchials and ceratobranchials (cf. Figs. 2A, 3A). Scale $\mathrm{bar}=10 \mathrm{~cm}$.

Colorado specimen (DMNH 63794) is particularly significant because it is the most complete among the three known skulls, and extends the known geographic and temporal range of Rhinconichthys to the Turonian of the Western Hemisphere. Comparison of DMNH 63794 with the specimens from England and Japan reveals that all three are distinct species. We follow the osteological terminology of Westoll (1943) and Arratia (2013).

\section{Institutional abbreviations}

BA, Staatliches Museum für Mineralogie und Geologie, Dresden, Germany; DMNH, Denver Museum of Nature and Science, Denver, Colorado, USA; KUVP, University of Kansas Vertebrate Paleontology Collection, Lawrence, Kansas, USA; NHMUK , Natural History Museum, London, UK; NSM, National Museum of Science and Nature, Tsukuba, Ibaraki (formerly in Tokyo), Japan; SDSM, Museum of Geology, South Dakota School of Mines, Rapid City, South Dakota, USA.

\section{Anatomical abbreviations}

ang, angular; ant, antorbital; ar, articular; boc, basioccipital; cb, ceratobranchials; chy, ceratohyal; cl, cleithrum; de, dentary; dpt, dermopterotic; dsph, dermosphenotic; eb, epibranchial; ept, ectopterygoid; eth, ethmoid; ex, exoccipital; gr, gill rakers; gu, median gular plate; hy, hyomandibula; hyb, hypobranchial; hyp, hypohyal; mpt, metapterygoid; mx, maxilla; op, opercle; pa, parietal (='frontal' traditionally); par, parasphenoid; pec.f, pectoral fin; pop, preopercle; ppa, postparietal (= 'parietal' traditionally); prear, prearticular; qu, quadrate; rad.p, pectoral radial; rodet, rostrodermethmoid; scl, sclerotic ring; sco, scapulocoracoid; sop, subopercle; sorbc, supraorbital sensory canal; spo, sphenotic; sy, symplectic.

\section{Systematic paleontology}

Class Osteichthyes Huxley, 1880

Subclass Actinopterygii Woodward, 1891

Order Pachycormiformes Berg, 1937

Family Pachycormidae Woodward, 1895

Genus Rhinconichthys Friedman, Shimada, Martin, Everhart, Liston, Maltese, and Triebold, 2010

Type species and type locality: Rhinconichthys taylori Friedman et al., 2010, from the Lower Chalk (Upper Cretaceous, Cenomanian), Burham, Kent, UK.

Diagnosis. (emended from Friedman et al., 2010): Edentulous pachycormid with the following combination of characters: squat skull roof dominated by large parietals; parietals fused along all but posterior-most median union; postparietals unsutured and separated by median gap; elongate supramaxillae along dorsal margin of maxillae; jaws slender and elongate (dentary length over height ratio $=12: 1)$; dentaries strongly bowed near symphysis with prominent ovoid swelling at symphysis; jaw articulation far posterior of skull roof; sclerotic rings comparatively large; orbits located above anterior portion of maxillae; exceptionally long and slender posterior projections of dermopterotics; exceptionally large, laterally compressed, elongate hyomandibulae lacking opercular processes and expanded at posterodistal end.

Included species. Rhinconichthys cf. R. taylori from the Upper Cretaceous Mikasa Formation in Mikasa City, Hokkaido, Japan; and new species represented by DMNH 63794 from southeastern Colorado, United States.

\section{Rhinconichthys purgatoirensis sp. nov.}

Etymology. Named after the Purgatoire River drainage of southeastern Colorado, the primary geomorphological feature of the type locality.

Type specimen. DMNH 63794 (holotype and only known specimen) consisting of nearly complete skull, pectoral girdles, and proximal portions of pectoral fins (Figs. 2-5).

Type locality and horizon. Lowermost part of Fairport Chalk Member, Carlile Shale, north fork Jack Canyon Arroyo, tributary of Purgatoire River, Otero County, Colorado, United States. DMNH 63794 comes from roughly $2.5 \mathrm{~m}$ above the first occurrence of the ammonite Collignoniceras woollgari (lower middle Turonian). A chalky limestone bed $1.25 \mathrm{~m}$ below occurrence of DMNS 63794 is equivalent to the upper-most bed of the Greenhorn Limestone in central Kansas ('Fencepost Limestone' bed; Hattin, 1975) and equivalent to 'Bed 134 ' of the Global Boundary Stratotype section for the Cenomanian-Turonian boundary at Pueblo Reservoir, Colorado (Cobban and Scott, 1972; Kennedy et al., 2005).

Diagnosis. Rhinconichthys with the following combination of characters - postparietals triangular and relatively elongate, widely separated and pointed anterior extent; parietals extend to lateral mid-point of postparietals; hyomandibulae with straight, nonundulating margins, gradually expanding from narrow anteroproximal to inflated posterodistal end; lower jaws protrude anteriorly beyond the rostrodermethmoid; pectoral fins with minimally 34 bifurcating fin rays that merge in symmetrical Y- 
pattern at leading edge; leading edge of proximal-most part of pectoral fin lacking ornamentation (smooth).

Description. The specimen was preserved wholly contained in a single spheroid concretion. The skull and pectoral girdles have largely been prepared free from the concretion, and the pectoral fin remains as part-counterpart on the small portion of concretion broken free during geologic sampling. The skull is crushed and extremely thin, measuring no more than $1.5 \mathrm{~cm}$ in maximum thickness. As preserved, the skull is skewed laterally, providing excellent views of the skull roof (Fig. 2) and left ventrolateral aspect (Fig. 3). Dermal elements of the skull are extremely thin (roughly $0.2 \mathrm{~cm}$ in thickness). Sutures, particularly those of the skull roof, are subtle and difficult to discern. Distance from the anteriorly protruded mandible to the posterior edge of the subopercle in left lateral view (Fig. 3) is $33 \mathrm{~cm}$. Pectoral fin rays are represented by part and counter-part, and measure $10 \mathrm{~cm}$ in maximum dimension (Fig. 4). Distance from the anterior end of the mandible to the pectoral fin base is $37.5 \mathrm{~cm}$.

Skull roof and braincase - The skull roof (Fig. 2) is a pentagonal shape with the anterior end marked by a blunt rostrodermethmoid. The posterior end is marked by a exceptionally long and slender projections of the dermopterotics. From the anterior end of the rostrodermethmoid to the terminal end of the dermopterotic posterior processes (left side complete), the skull roof measures $25 \mathrm{~cm}$ (=cranial length). The widest portion of the skull is near the midpoint of the dermopterotics, measuring approximately $12.5 \mathrm{~cm}$ (=cranial width). The rostrodermethmoid is about $4.5 \mathrm{~cm}$ long and $4 \mathrm{~cm}$ wide, with a gently convex anterior margin and lateral sides with a slight constriction. The posterior margin of the rostrodermethmoid is V-shaped and wedges in between the parietals. The parietals are fused together posterior to their articulation with the rostrodermethmoid. The parietals are large and elongate, $9.5 \mathrm{~cm}$ in length and $3.5 \mathrm{~cm}$ in maximum width. The anterior half of the parietals are ornamented with faint radial ridges. Posterior portions of the parietals articulate medially with the postparietals and laterally with the dermosphenotics. A faint groove likely to represent the supraorbital sensory canal extends from the middle of the medial concavity anteriorly, visible on the right parietal (Fig. 2). The dermosphenotic is elongate, measuring roughly $5 \mathrm{~cm}$ long and $1 \mathrm{~cm}$ wide, and forms the lateral margin of the skull along with the parietals anteriorly and the dermopterotics posteriorly. Each postparietal measures about $5 \mathrm{~cm}$ long and $2 \mathrm{~cm}$ wide, articulating with the posteromedial margin of the parietal anterolaterally and with the medial margin of the dermopterotic laterally. The medial margins of the postparietals are convex, but the elements do not make contact and are separated by a $0.5-1 \mathrm{~cm}$ gap. The dermopterotic is tri-radiate, and a medially-directed extension articulates with the postparietal. The dermopterotic measures roughly $9 \mathrm{~cm}$ in length and $3.5 \mathrm{~cm}$ mediolaterally, and comes into contact with the parietal and dermosphenotic anteriorly. Exoccipitals are discernable posterior to the postparietal and dermopterotic, but their morphology is unclear (Fig. 2).

Orbital and Opercular area - The orbit is lateroventral to the dermosphenotic (Fig. 2, 3) and is marked by a sclerotic ring that consists of anterior and posterior elements. The inner and outer margins of the left sclerotic ring measure approximately $2.3 \mathrm{~cm}$ and $3.8 \mathrm{~cm}$ in diameter, respectively (Fig. 3). In relation to the sclerotic ring, anteroventrally is a small bone that may be an antorbital, and posteroventrally is a large flat bone likely to be the ectopterygoid-metapterygoid complex (Fig. 3). The sphenotic, a robust lateral projection, forms the lateroventral margin of the skull roof immediately posterior of the sclerotic ring (Fig. 2). The hyomandibula is large and elongate, measuring $15.8 \mathrm{~cm}$ long and roughly $4 \mathrm{~cm}$ in maximum width. The hyomandibula articulates with the otic region beneath the sphenotic, and extends along the lateral side of the cranium to beyond the quadrate. The dorsal and ventral edges of the hyomandibula are straight, and both terminal ends are rounded, but the proximal (orbital) end is more tapered than the expanded distal (articular) end (Fig. 2). Overall the hyomandibula is a large, oar-shaped flat bone, lacking any process to articulate with the opercle (Fig. 3). Although poorly preserved, staining and bone grain in matrix indicate the opercle followed posteriorly by the subopercle, together forming a closely conforming pair roughly $13 \mathrm{~cm}$ in length and $5 \mathrm{~cm}$ in height. The quadrate has a 3.5 -cm-long dorsal surface, a robust well-defined semicircular ventral condyle, and a convex anterior margin (Fig. 3). The preopercle, a thin elongate element $6 \mathrm{~cm}$ long and $1.4 \mathrm{~cm}$ wide, is oriented across the hyomandibula and quadrate (Fig. 3). Along the posterior margin of the left quadrate is a small bone interpreted to be the symplectic, and near the posterodorsal corner of the left quadrate is the occipital condyle (Fig. 3). The position of the occipital condyle is about $10 \mathrm{~cm}$ behind (posterior to) the skull roof.

Immediately posterior to the occipital condyle are four slender bony rods, interpreted from position, orientation and the crushing pattern to be the left ceratobranchials of the gill arches (Fig. 3). Several of the ceratobranchials continue to the other side of the slab immediately medial to the ascending ramus of the left cleithrum (Fig. 2). A similar set of at least four skeletal rods of the gill basket are preserved near the parasphenoid (Fig. 2). An X-ray image (Fig. 5) vividly depicts epibranchials and ceratobranchials originating from the level of the posterior margin of the skull roof and extending posteriorly to the level of the pectoral fin bases, measuring $16.5 \mathrm{~cm}$ long. Neither gill rakers nor detached aci fanunculorum ('needle of the raker', sensu Liston, 2013) are associated with these branchial rods.

Jaws and Suspensorium - The edentulous maxilla is slender and nearly straight, and the complete element (left) measures $19.5 \mathrm{~cm}$ long and $1.75 \mathrm{~cm}$ deep. The maxilla parallels the cranial roof margin from the posterior point of the rostrodermethmoid to the anterior margin of the quadrate (Figs. 2,3). The anterior end of the maxilla is pointed and seemingly does not articulate with any bones (or none preserved), whereas the posterodorsal margin has a concave surface that likely contacts the anterior margin of the quadrate when the jaws protract (see Section 5). The left maxilla is demarked along the dorsal rim by an elongate splint of bone that is interpreted to be the supramaxilla (Fig. 3). Similar distinct splints of bone are visible above the maxillae in other Rhinconichthys specimens (see below).

The bulk of the edentulous mandible consists of slender, elongate dentaries that are strongly bowed near the anterior end (Fig. 3), and merge together with a prominent ovoid articular swelling at the symphysis (Fig. 2). Each dentary measures $22.5 \mathrm{~cm}$ in maximum length and is followed posteriorly by a short angular (Fig. 3). The jaw terminates posteriorly with a concave articular bone that receives the ventral condyle of the quadrate. A narrow prearticular projects from beneath the posteroventral margin of the left mandible, likely displaced from its position mesial to the dentary and angular (Fig. 3). The maximum length of the mandible is $25.5 \mathrm{~cm}$, and the greatest width between at the middle of the dentary rami is approximately $6 \mathrm{~cm}$. The anterior end of the jaw symphysis is situated $2 \mathrm{~cm}$ further anteriorly than the tip of the rostrodermethmoid (Fig. 2), indicating a distinct 'under-bite' of the lower jaws. We conclude this 'under-bite' is genuine and not an artifact of taphonomic distortion, as verified by measurements from the posterior edge of the left quadrate to the anterior tip of rostrodermethmoid $(25 \mathrm{~cm})$ and to the anterior tip of dentaries $(27 \mathrm{~cm})$.

Between the anterior portions of the dentaries is an egg-shaped gular plate (Fig. 3). The gular measures roughly $5 \mathrm{~cm}$ long and 
$2.5 \mathrm{~cm}$ wide, and the anterior margin does not extend to the inner margin of the lower jaw symphysis leaving a 2.5 -cm-long empty gap. Dorsal to the gular plate are stout, recurved 3.5-cm-long elements interpreted to be hypohyals, visible on the dorsal surface between the dentaries and rostrodermethmoid (Figs. 2 and 5). Note that the hypohyals were mistakenly identified as lateral barbs of the rostrodermethmoid in preliminary assessment by Schumacher and Maltese (2013). The hypohyals are bowed to parallel the curvature of the dentary, have flat and oval-shaped anterior ends, and gradually taper posteriorly. Robust ceratohyals are present between the dentaries, each starting from somewhere dorsal to the gular (not visible) and extending to at least the level of the dentary-angular junction (Fig. 3). The lateral surface of the left ceratohyal is smooth and subtly convex. The medial surface of the right ceratohyal is subtly concave, bearing a broad groove along its length.

Pectoral fins and girdles - At the posterior ends of the ceratohyals is a slender right cleithrum (Fig. 3), which extends posteriorly slightly beyond the subopercle and articulates with the right scapulocoracoid laterally. The left cleithrum is represented only by its ascending posterior ramus immediately posterior to the subopercle, and is partially observable from both sides of the specimen (Figs. 2, 3). Several 2-cm-long pectoral radials articulate with the scapulocoracoid. Each pectoral radial is 'hourglass'-shaped and flared more prominently at the proximal (scapular) end. Only a few right pectoral radials are preserved (Fig. 3), but as many as 12 left pectoral radials are stacked to form the pectoral fin base (Fig. 2). All of the elements appear similar, and distinctive morphology of the first (proterygium) pectoral radial is not evident. Pectoral fins are represented by a small basal portion of both fins in the skullbearing slab (Fig. 3) and a separate proximal portion of the right pectoral fin (Fig. 5) severed during discovery testing of the concretion. The right pectoral fin preserves 34 non-segmented, bifurcating fin rays, and the bifurcations merge along the leading edge of the fin with no ornamentation (Fig. 5). Distance from the anterior end of the mandible to the pectoral fin base is $37.5 \mathrm{~cm}$.

Rhinconichthys taylori Friedman, Shimada, Martin, Everhart, Liston, Maltese, and Triebold, 2010

2010 Rhinconichthys taylori Friedman et al.,

Type specimen. NHMUK PV OR 33219 (holotype and only known specimen of this species) consisting of partial three-dimensional skull from Lower Chalk (Upper Cretaceous, Cenomanian), Burham, Kent, UK (Fig. 6).

Diagnosis (emended from Friedman et al., 2010). Rhinconichthys with the following combination of characters; postparietals relatively elongate and nearly united along length (separated only by a narrow slit), and with rounded anterior extent; concave lateral edges of postparietals restricted by posterior extensions of parietals; parietals extend nearly to posterior edge of skull roof; dorsal margin of hyomandibulae sinusoidal, posterior one-half of dorsal margin with distinct convexity.

Description. The incomplete skull is three dimensional, with the anterior and posterior extremities missing. The skull roof is broken irregularly, and the opercular series is absent. The posterior portions of the lower jaws are also missing. The maximum length of the skull from the anterior end of the right dentary to the posterior end of the preserved left dermopterotic is roughly $22 \mathrm{~cm}$ (Fig. 6D).

Skull roof and braincase - Most bones of the skull roof are incomplete (Fig. 6D) but offer adequate information to ascertain overall cranial roof architecture. The anterior-most portion of the skull roof is missing, and thus the shape of the rostrodermethmoid can only be inferred by the underlying palate. The right parietal is nearly complete although missing the anterior end. The left parietal is represented by the anterior and posterior ends (middle portion is missing), and the parasphenoid is exposed below the missing area. Both parietals are sufficiently preserved to suggest that a complete element is roughly $10 \mathrm{~cm}$ long and $3.5 \mathrm{~cm}$ wide, with an overall curved ovoid shape. The right parietal shows a faint, posteromedially directed supraorbital sensory canal on the distal half. Elongate posterior processes of the parietals curve medially and slightly overlap the lateral edges of the postparietals. Each postparietal has a rounded anterior end, gently convex anterolateral edge, concave posterolateral edge, and straight medial and posterior margins. The postparietals form a broad V-shape at their posterior ends, and the preserved potion of both medial edges (posterior) are slightly separated by a narrow slit-like gap. The left dermopterotic is $5.5 \mathrm{~cm}$ at its widest point, and the lateral edges of both dermopterotics are slightly concave. The left dermopterotic trends to an elongate and slender posterior projection. The exact posterior extent of the dermopterotic is uncertain due to breakage, but the preserved portion on the left side measures $6.5 \mathrm{~cm}$ (Fig. 6D). The dermosphenotic (Fig. 6A, D) is lateral to the dermopterotic and defines the dorsal border of the orbit on both sides. The anteroposterior length of the cranial roof between the estimated tip of the missing rostrodermethmoid and the preserved extent of the left dermopterotic measures roughly $19 \mathrm{~cm}$. The widest point of the cranial roof measures $11.5 \mathrm{~cm}$ at the midpoint of the dermopterotics. In lateral view (Fig. 6A, B) the skull is triangular, with a maximum skull depth of $11 \mathrm{~cm}$ at the posterior border, and the skull roof steeply inclined to the anterior border.

Behind the postparietals are portions of plate-like exoccipital bones (Fig. 6D). The occipital condyle is not preserved, but the basioccipital is observable on the right side (Fig. 6A), and the middle portion and the anterior tip of the parasphenoid are exposed through missing portions of the skull roof (Fig. 6D). The preserved parasphenoid-basioccipital measures $14 \mathrm{~cm}$ in length.

Opercular area - The orbit is below the dermosphenotic and contains two (anterior and posterior) arched sclerotic ossifications. Both right and left sclerotic rings are displaced laterally (Fig. 6C), but their inner and outer diameters measure $3 \mathrm{~cm}$ and $5 \mathrm{~cm}$, respectively. The left sclerotic ring is incomplete (Fig. 6B), but the right is nearly complete and relatively undistorted other than lateral displacement. The proximal end of the hyomandibula originates immediately at the posterodorsal rim of the orbit and ventral to the dermosphenotic (Fig. 6A, B). The left hyomandibula (Fig. 6B) is nearly complete, is $15 \mathrm{~cm}$ in maximum length, and bears a sinuous dorsal margin with a prominent convexity along the distal one-half. The left hyomandibula is orientated nearly horizontal, and has a ventral inflection at the left quadrate (Fig. 6B). Below the left hyomandibula (Fig. 6B) are flat fragmentary bones interpreted to be portions of the ectopterygoid and metapterygoid. Several small portions of epibranchials and ceratobranchials are exposed between the left hyomandibula and ectopterygoid-metapterygoid complex (Fig. 6B). Similar slender bony rods are preserved on the right side, some of which (ceratobranchials) extend from the medial side of the dentary to the posterior end of the specimen (Fig. 6A). Gill rakers and detached aci fanunculorum (sensu Liston, 2013) that could be associated with these rods are visible behind the left orbit (Fig. 6B; see Friedman et al., 2010, Fig. S3B).

Jaws and Suspensorium - Major jaw elements consist of the maxilla-supramaxilla upper jaw components and the dentaries. The left side shows the jaws articulating with the quadrate (Fig. 6B), whereas posterior jaws and quadrate are not preserved on the right side (Fig. 6A). The left maxilla is nearly complete, measuring $17 \mathrm{~cm}$ long with a straight edentulous ventral margin (Fig. 6B). The left maxilla ranges from $0.5 \mathrm{~cm}$ to $1.5 \mathrm{~cm}$ deep in the anterior portion, widening to about $1.75 \mathrm{~cm}$ at the posterior end. The point at which the maxilla widens coincides with the posterior termination of the 

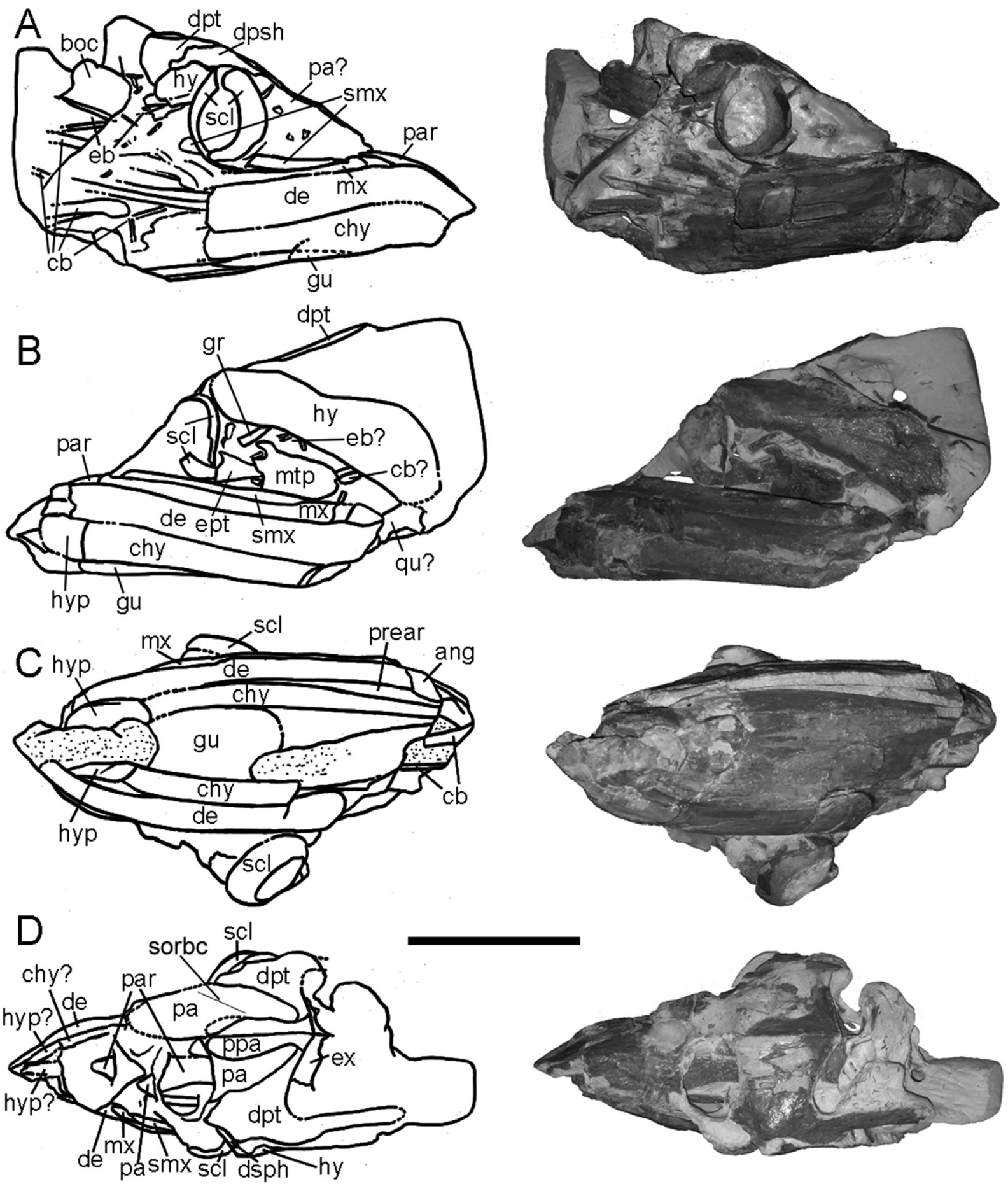

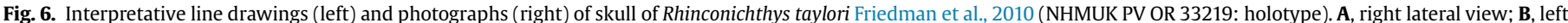
lateral view; C, ventral view; D, dorsal view. Scale bar $=10 \mathrm{~cm}$.

slender, juxtaposed supramaxilla. The supramaxilla is $11 \mathrm{~cm}$ long and $0.3 \mathrm{~cm}$ deep, and does not reach the anterior tip of the maxilla. The dentary is massive as compared to the upper jaw (Fig. 6A, B). The anterior end of the dentary is missing on the left side (Fig. 6B), but it is preserved on the right side and exhibits a prominent ventral bend (Fig. 6A). Combined information from both dentaries suggests that the maximum length and depth is $21 \mathrm{~cm}$ and $2.5 \mathrm{~cm}$, respectively. The dentaries extend much further anteriorly than the maxillae. The anterior symphysis is not preserved on either dentary, but the dentaries are strongly bowed (Fig. 6C) along the anterior portions. In ventral view, the left angular is visible behind the left dentary (Fig. 6C), along with a narrow, anteriorly-tapering portion of the left prearticular between the posterior ceratohyal and dentary. The arched ceratohyals trend parallel along the medial margin of the dentaries, with a greater portion of the left element preserved (Fig. 6C). Robust hypohyals are present immediately anterior to the ceratohyals, and a shield-like oval gular plate is present between the anterior half of the ceratohyals (Fig. 6C). 
Rhinconichthys uyenoi sp. nov.

2010 Rhinconichthys cf. R. taylori Friedman et al.,

Etymology. Named in honor of Dr. Teruya Uyeno, curator emeritus of NSM, for his contribution to ichthyology and paleoichthyology. Type specimen. NSM VP21868 (holotype and only known specimen of this species) consisting of partial three-dimensional skull (Fig. 7); cast of this specimen catalogued as NHMUK PV P.66822.

Type locality and horizon. Upper Cretaceous (likely Cenomanian) Mikasa Formation, Middle Yezo Group, Ikushumbetsu, Mikasa City, Hokkaido, Japan.

Diagnosis. Rhinconichthys with the following combination of characters; postparietals triangular, short and widely separated; parietals extended at posteromedial borders to meet shorter postparietals; parietals separated along posterior midline; hyomandibulae with near parallel dorsal and ventral margins, relatively uniform in width from orbital end to articular end.

Description. The incomplete skull is three dimensional, and lacks the anterior and posterior extremities. The posterior portion of the skull roof region is well preserved, and the anterior cross-sectional view provides unique information about the shape and internal arrangement of ceratohyals and hypobranchial elements.

Skull roof and braincase - The cranial roof includes the posterior portions of the parietals and dermosphenotics, complete postparietals, and dermopterotics with incomplete posterior projections (Fig. 7E). More of the left parietal is preserved and shows a bluntly pointed posterior end, rounded lateral edge, and a straight medial edge. The posteromedial edge of the parietals closely conform with the slanted anterolateral edge the postparietals, but the elements are not sutured. Each postparietal has a maximum length and width of about $8.5 \mathrm{~cm}$ and $5.5 \mathrm{~cm}$, respectively. A gap exists between the common border of both the parietals and postparietals, and is widest (about $2 \mathrm{~cm}$ ) at the anterior one-half of the postparietals. The dermopterotic is present lateral to each postparietal. The left dermopterotic has a concave anterior margin that articulates with the convex posterior edge of the left dermosphenotic. The posteromedial and posterolateral margins of the dermopterotic are concave and trend to rod-like posterior projections. Although the posterior projections of both dermopterotics are broken, each extends well beyond the skull roof. Two parallel bony ridges extend behind the postparietals, and these ridges are possibly the dorsolateral margins of the basioccipital as they occupy the same position relative to the skull roof in Rhinconichthys. taylori (see Fig. 6A). Several fragmentary rod-like bones between the basioccipital and dermopterotic extensions are interpreted as epibranchials, along with stalks (Liston, 2013) of gill rakers. The widest part of the preserved skull measures $23 \mathrm{~cm}$ between the dermopterotics.

Opercular area - The dermopterotics have extensive lateral expression, and paired anterior and posterior sclerotic ossifications are on both sides of the skull anteroventral to the dermopterotics (Fig. 7A, B). Although sclerotic rings are displaced, estimation of the undistorted left side yields measurements of $7.5 \mathrm{~cm}$ and $10 \mathrm{~cm}$ for inner and outer edge diameters, respectively (Fig. 7B). The left hyomandibula is largely preserved although missing the proximal and distal ends. Notably, the dorsal and ventral margins of the hyomandibula are nearly parallel, although the element does flare slightly at the preserved posterior (distal) end. Along the lateral surface of the left hyomandibula is a vertically oriented slender element interpreted as a preopercle (Fig. 7B).

Jaws and Suspensorium - Jaw elements include the maxillaesupramaxillae of the upper jaws and the dentaries-prearticulars of the lower jaws (Fig. 7A, B). The maxillae have a subtly concave dorsal margin, a straight ventral margin, and a dorsal inflection at the anterior ends, and the posterior ends of both are broken. The supramaxillae are narrow and straight, resting on the gently concave dorsal margin of the maxilla. The edentulous dorsal margin of the dentary is straight except the anterior portion (left side, Fig. 7B) where it curves upward to occlude with the anterior portion of the maxilla. The ventral margin of the dentaries are straight, and posterior extremities are missing. Substantial portions of prearticulars are present at the posteroventral margin of each dentary (Fig. 7A, B). A slender bone interpreted to be the angular is present between the prearticular and ceratohyal on the right side (Fig 7C).

In ventral view, the robust, arching ceratohyals are present medial to the dentaries (Fig. 7C). A thin, oval gular plate is poorly preserved, but remnants of this element cover the anterior-most portion of the ceratohyals. The broken anterior surface (Fig. 7D) reveals that the ceratohyals are ovoid in cross-section, and trend parallel to and are thicker than the dentaries. Smaller bones in cross-section between the ceratohyals may include hypobranchials (Fig. 7D).

\section{Discussion}

\subsection{Comparisons and taxonomic remarks}

The Family Pachycormidae contains two distinct ecological tribes referred to as billfish or barracuda-like (tusked) forms and suspension-feeding (toothless) forms (Friedman, 2012; Liston and Friedman, 2012). Bonnerichthys was recently recognized to be a Cretaceous representative of the edentulous tribe (specimens previously misinterpreted as Protosphyraena) and is documented solely in North America from Coniacian through Maastrichtian time (Friedman et al., 2010, 2013). Two Rhinconichthys specimens from Europe (NHMUK PV OR 33219) and Japan (NSM VP21868) were also previously recognized among suspension-feeding pachycormids (Friedman et al., 2010), and here are diagnosed as two distinct species (R. taylori and R. uyenoi sp. nov.).

Rhinconichthys purgatoirensis sp. nov. has unique morphologies distinguishing it from other Rhinconichthys species, and is certainly peculiar among any other pachycormid thus far described in the Western Hemisphere. The absence of ossified or mineralized vertebral centra, and non-segmented and bifurcating fin rays firmly establish $R$. purgatoirensis, and Rhinconichthys as a whole, within the Family Pachycormidae. The minimum fin ray count of 34 is high among pachycormids as a whole, similar to Bonnerichthys (Loomis, 1900; Hay, 1903; Stewart, 1988; Arratia and Schultze, 2013; Maltese and Liston, 2014).

There are several morphological features that separate Rhinconichthys taylori, $R$. purgatoirensis sp. nov., and $R$. uyenoi sp. nov., particularly the architecture of the skull roof and the shape of the hyomandibula (Fig. 8). Other conditions are less certain, such as the rostrodermethmoid which is only preserved in R. purgatoirensis sp. nov.. Posterior extensions of the parietals wrap posterolaterally around the postparietals in $R$. purgatoirensis sp. nov., whereas they extend posteromedially and lap onto the postparietals in $R$. taylori, and abut bluntly against the short postparietals of $R$. uyenoi. Postparietals of $R$. purgatoirensis sp. nov. are elongate and triangular, those of $R$. taylori have concave lateral edges and rounded anterior tips, and those of $R$. uyenoi sp. nov. are much shorter and triangular. The hyomandibulae of all three species are remarkably elongate and lack an opercular process, but the margins are nearly parallel and anteriorly tapering in $R$. purgatoirensis sp. nov., sinusoidal with a concave dorsal margin in $R$. taylori, and nearly parallel in $R$. uyenoi sp. nov.. These differences among Rhinconichthys specimens are substantial, and elicit the separation of each as a distinct species.

Collectively, the three Rhinconichthys specimens provide a clear sense of skull bone patterns and dimensions for the genus. 

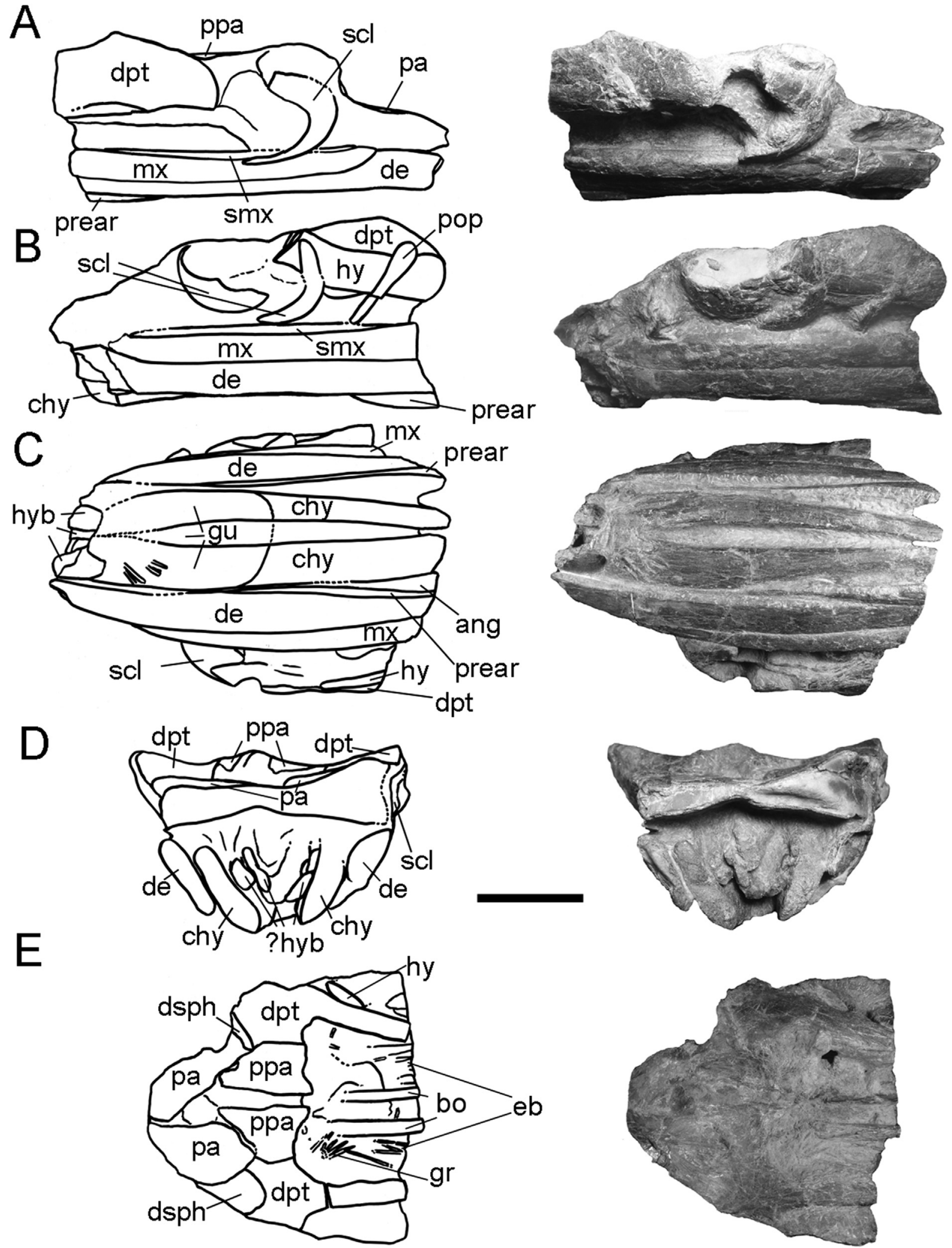

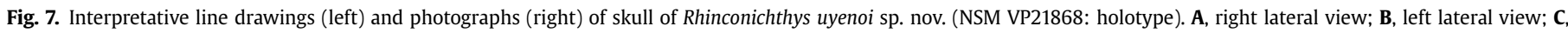
ventral view; D, anterior (cross-sectional) view; E, dorsal view. Scale bar $=10 \mathrm{~cm}$. 


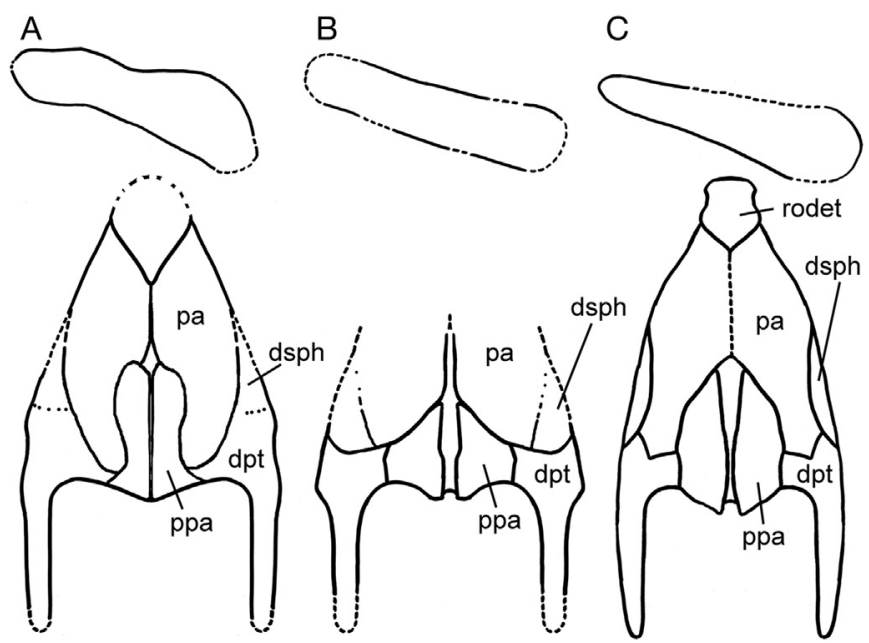

Fig. 8. Schematic interpretations of hyomandibula (above) and skull roof (below) for each Rhinconichthys species based on holotype. A, Rhinconichthys taylori Friedman et al., 2010, based on NHMUK PV OR 33219 (extrapolated from Fig. 6D); B, Rhinconichthys uyenoi sp. nov. based on NSM VP21868 (extrapolated from Fig. 7E); C, Rhinconichthys purgatoirensis sp. nov. based on DMNH 63794 (extrapolated from Fig. 2A). All skulls depicted at same scale.

The three-dimensional skull of $R$. uyenoi sp. nov. provides particularly valuable cross-sectional views that help to understand the relations of branchial and hyoid elements (i.e. hypobranchials, ceratohyals) with the lower jaw. Comparisons of $R$. purgatoirensis sp. nov. and $R$. uyenoi sp. nov. with the type species $R$. taylori leaves little uncertainty that the three species are congeneric because of multiple shared apomorphies, such as a short skull roof, un-sutured union of postparietals, remarkably elongate posterior projections of the dermopterotics, and exceptionally large and elongate hyomandibulae lacking an opercular process.

\subsection{Head shape and speculative body form}

Rhinconichthys has a slender pointed head with a flat cranial roof. Based on the position of the opercular series and cleithra in $R$. purgatoirensis sp. nov. (Figs. 2, 3), the length versus width of the head is roughly $3: 1$. The head is triangular in lateral view with a large eye situated near the front. $R$. purgatoirensis sp. nov. indicates the genus has a sharply tapered snout. The lower jaws protrude anteriorly well in front of the rostrodermethmoid, a characteristic shared with the Jurassic edentulous pachycormid Martillichthys (e.g. Liston, 2008). The lateral bowing of the dentaries does not match the upper jaws. Given both the under-bite and lateral bowing of the dentaries, it is conceivable that jaw occlusion in these forms was not an important function, and sealing the oral cavity would have required soft tissue. The elongate, slender nature of the jaw elements in Rhinconichthys is remarkable, especially evident from the dentaries which are 12 times longer than their maximum height. The elongate supramaxilla is also unique, and in the broader group of pachycormids (Asthenocormus, Orthocormus, and Pachycormus) is restricted to the posterodorsal border of the maxilla (Mainwaring, 1978; Lambers, 1992).

Lengths of the skull roof and the opercular series are nearly equal, indicating that Rhinconichthys had a large, elongate gill basket. Elaborate gill rakers are most certainly an important functional component of the gill arches, and small fragments of such structures are preserved with $R$. taylori (Friedman et al., 2010) and
$R$. uyenoi sp. nov.. No gill rakers or associated structures are preserved with $R$. purgatoirensis sp. nov..

No evidence of mineralized vertebral centra are present. Contextual articulation of specimens such as $R$. purgatoirensis sp. nov. strongly suggests that vertebral components are not ossified, and the axial skeleton was largely cartilaginous as in other pachycormids (Loomis, 1900; Hay, 1903; Liston, 2008; Liston et al., 2013). No anatomical elements of the trunk or fins (dorsal, pelvic, anal, or caudal) are known, other than the pectoral material of $R$. purgatoirensis sp. nov.. The pectoral fins and girdles of $R$. purgatoirensis sp. nov. are preserved in life position with the skull, but only the proximal-most portions of pectoral fins are preserved. Pectoral fin ornamentation is not uniform across Pachycormidae. Those taxa that exhibit marked ornamentation on the leading edge of fins often lack specialized ornament at the proximal margin, as is the case in Bonnerichthys and Protosphyraena (Loomis, 1900; Stewart, 1988; Friedman et al., 2013). Therefore, whether the leading edge of Rhinconichthys pectoral fins is ornamented as in some other pachycormids remains unknown. The unusually long pectoral fins common throughout Pachycormidae appear to have developed in conjunction with otherwise reduced skeletal ossification in some pachycormids, perhaps in part to counteract buoyancy problems (Freedman and Noakes, 2002; Maltese and Liston, 2014). The length of pectoral fins in Rhinconichthys is unknown, but comparison with other suspension-feeding pachycormids suggests that the pectoral fins would have a low aspect ratio, to enhance and sustain lift during low velocity protracted suspensionfeeding (Maltese and Liston, 2014). This notion is supported by the relatively large size and breadth of the pectoral fin bases in $R$. purgatoirensis sp. nov. as compared to its skull. Thus, we speculate the total length of the DMNH 63794 pectoral fin would be roughly $38 \mathrm{~cm}$ (see Description above), with overall morphology that of a large and broad fin.

\subsection{Size estimation}

Nearly all of the post-cranial anatomy for Rhinconichthys is unknown, although some assumptions can be made. Rhinconichthys taylori (NHMUK PV OR 33219) is relatively small, and thus the individual may represent a juvenile, or could indicate that $R$. taylori is overall a smaller species. Rhinconichthys uyenoi sp. nov. (NSM VP21868) is robust and is slightly larger than the other Rhinconichthys specimens; therefore, it may represent an adult, but comparison is complicated by the missing anterior and posterior skull extremities. In contrast, $R$. purgatoirensis sp. nov. (DMNH 63794 ) is a nearly complete skull, and its well-ossified and sutured cranial elements suggest that the individual is an adult form. Although the single specimen representing $R$. purgatoirensis sp. nov. (DMNH 63794) is not the largest specimen of Rhinconichthys, its association with pectoral girdles provides a better means for size extrapolation.

Dimensions of more complete edentulous pachycormid skeletons are scaled to $R$. purgatoirensis sp. nov. (DMNH 63794) as a means to estimate an adult length for the genus Rhinconichthys. Asthenocormus (BA J2344) possesses a skull roughly $28 \mathrm{~cm}$ in length and a standard total length of $132 \mathrm{~cm}$ (Liston, 2008). Therefore, the skull of Asthenocormus constitutes $21 \%$ of its total length, and scalar comparison with the skull of $R$. purgatoirensis sp. nov. yields an estimated length of $1.7 \mathrm{~m}$. However, the referenced specimen of Asthenocormus (BA J2344) is juvenile, which presents problems for scaling due to potential allometry (Liston, 2008). Martillichthys (NHMUK PV P.61563), which R. purgatoirensis sp. nov. more closely resembles, has a more elongate ('eel-like') body form, possessing a skull length of $37 \mathrm{~cm}$ (17.5\% of the total body length) and a standard total length of $2.1-2.3 \mathrm{~m}$ (Liston, 2008). Different scalar 
comparisons with the Martillichthys specimen produce varying total length estimates for $R$. purgatoirensis sp. nov. ranging from 2.0-2.7 $\mathrm{m}$. The two other known specimens of Rhinconichthys (NHMUK PV OR 33219, R. taylori; NSM VP21868, R. uyenoi sp. nov.) contain similar-sized cranial material, although $R$. uyenoi sp. nov. is slightly larger. From this information, we conclude that $R$. purgatoirensis sp. nov. is moderate in size with adults ranging between 2.0 and $2.7 \mathrm{~m}$ in total length. These are rather modest size estimates for a clade known to produce exceptionally large animals, such as Bonnerichthys and Leedsichthys that reached at least up to $5 \mathrm{~m}$ and $16.5 \mathrm{~m}$, respectively (see Friedman et al., 2010; Liston et al., 2013). Sclerotic ring size is a preserved variable present in all three known Rhinconichthys specimens. The retro-deformed maximum sclerotic dimension for $R$. uyenoi sp. nov. is $8.5 \mathrm{~cm}$, and that for $R$. purgatoirensis sp. nov. and $R$. taylori is $5 \mathrm{~cm}$. By this rather crude variable, the above size estimation can be extrapolated to $R$. uyenoi sp. nov. and yields a total estimated body length between 3.4 and $4.5 \mathrm{~m}$.

\subsection{Jaw kinematics and suspension feeding}

The most peculiar aspect of Rhinconichthys is the pair of prominent, highly elongate hyomandibulae. We consider this feature to be an important functional specialization that is key to the biology of Rhinconichthys. The elongate hyomandibulae served as massive levers to thrust the jaw articulation ventrolaterally through protraction, allowing for extraordinary expansion of the buccal cavity (Fig. 9). The hyomandibula lacks an opercular process, suggesting that lever-like motion required increased freedom from the opercular series, more so than in other pachycormids (e.g. the hyomandibula of Bonnerichthys has a prominent opercular process: Friedman et al., 2010). The proximal end of the hyomandibula is rounded, and has a firm but free articulation with the otic region behind the orbit. The distal end of the hyomandibula is enlarged, and this broad surface area would greatly depress and expand the lower jaws and gill arches ventrolaterally during protraction. The ventral condyle of the quadrate articulates with a posteriorly-facing concave articular surface of the lower jaw, thus making the quadrate a likely anchor point for levering action of the hyomandibula. The posterior margin of the maxilla slants posteroventrally, and may have been an anchor point for the convex anterior margin of the quadrate during jaw protraction. The maxilla is notably short anteriorly, terminating well short of the rostrodermethmoid tip, which may indicate ability of the upper jaw to move anterolaterally upon protraction. The lower jaw symphysis is characterized by a robust articular surface suitable for a tough but flexible ligamentous connection. As in other neopterygians, the ceratohyals and hypohyals are robust, serving as powerful anchor points for the gracile lower jaws. Given the slender nature of the dentaries, forces absorbed by the jaws are likely accommodated by the hyomandibulae and robust hyoid complex. The elongate, posteriorly directed dermopterotic extensions may serve to stabilize the highly kinetic hyomandibulae when the jaws retracted, and perhaps also support the opercular series which had lost articulation with the hyomandibulae.

Along with the edentulous condition of the jaws, the highly specialized jaw function indicates that Rhinconichthys was an obligate suspension-feeder. Rhinconichthys likely extracted mesoplanktonic prey items with an extensive gill basket including elaborate gill rakers. The posteriorly-directed epibranchials and ceratobranchials observed in all three species (Figs. 2-4, 6, 7) are strong indicators that Rhinconichthys had an elongate gill apparatus medial to the opercular series, thus maximizing the gill surface area
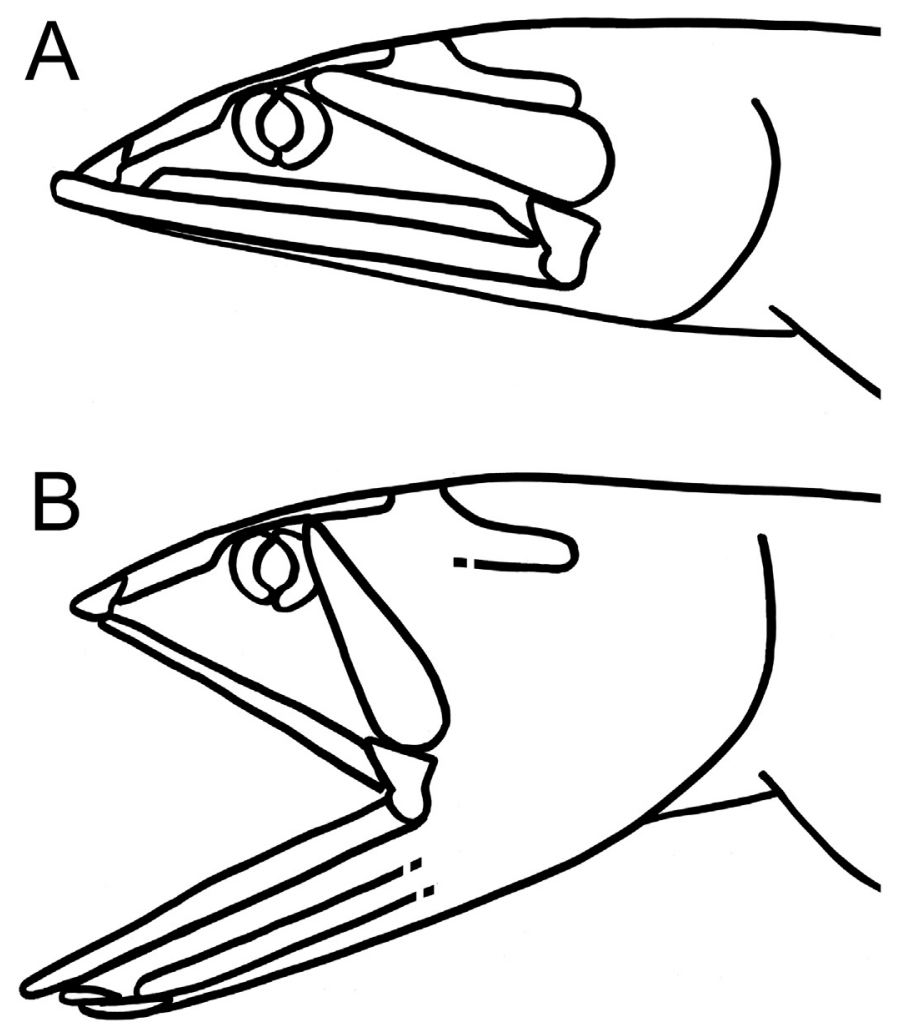

Fig. 9. Conceptual illustration of head of Rhinconichthys showing jaw kinematics. A, jaws in occlusion at rest; $\mathbf{B}$, jaws in protraction.

for prey capture. The parallel evolution of jaw mechanics in several unrelated but ecologically similar groups of fishes is wellestablished (Westneat, 2004). Levering on the large and elongate hyomandibulae, the jaw function of Rhinconichthys is likely to parallel that of extant acipenseriforms (Carroll and Wainwright, 2003), particularly the North American paddlefish Polyodon (Grande and Bemis, 1991; Burggren and Bemis, 1992) and sharks (Motta, 2004; Motta and Huber, 2012). The hyomandibula of Rhinconichthys possesses a broad range of post-axial movement hinging on the otic region (proximal end), ranging from near horizontal with jaws in occlusion, to near vertical with the jaws open and a substantial degree of lateral movement. This highly derived, early example of a novel jaw expansion mechanism presages the protrusible teleost jaw, as developed and elaborated upon in different ways by diverse neopterygians groups (Bowen, 1983; Westneat, 1995).

Lazzaro (1987) notes that the trend towards microphagy in teleost evolution carries several common characteristics, including the development of protrusible jaws, and the replacement of teeth by elaborate gill rakers on branchial arches, among others. The absence of gill rakers in DMNH 63794 is likely to be a matter of preservation. Gill rakers may not fully mineralize in life (van den Berg et al., 1994) which can present a particular obstacle to interpreting fossils as suspension-feeders (Liston, 2013). We note that gill rakers are similarly not preserved for any known specimen of Bonnerichthys, but gill rakers with associated Leedsichthys-like bifid attachments and fimbriae (sensu Liston, 2013) are known in $R$. taylori (Friedman et al., 2010). R. uyenoi shows apparent (although largely unprepared) blade-like gill raker stalks between branchial arch elements (Fig. 7E), similar to those seen in Martillichthys (Liston, 2008). 


\subsection{Paleoecology}

Rhinconichthys likely relied upon a form of ram ventilation for respiration as do many modern suspension feeders, including the paddlefish Polyodon (Burggren and Bemis, 1992). The propensity for fluid movement through the mouth is suggested by the seeming unimportance of jaw occlusion. The lower jaws extend beyond the tip of the rostrodermethmoid, and the straight maxillae do not conform to the bowed dentaries. The large, elaborate gill basket and the degree to which skull construction emphasizes expansion of the buccal cavity suggests Rhinconichthys spent a majority of its adult lifetime actively moving with the jaws agape.

The sclerotic rings of Rhinconichthys define comparatively large eyes, a feature retained despite radical transformation of skull construction toward microphagy. This indicates that vision was important in the habits of these fish, and contrasts markedly with the rather diminutive eyes of most modern suspension-feeding vertebrates. Vision is not an important factor for prey selection and capture in suspension-feeding sharks, rays, acipenseriforms, or baleen whales (Sanderson and Wassersug, 1993). Rhinconichthys may have relied more on eyesight to detect predators while following migrating mesoplanktonic organisms to the edge of the photic zone, and large eyes are often associated with animals that feed in low light conditions.

\subsection{Evolutionary perspectives}

The skull morphology and function of Rhinconichthys is markedly different than the related and near contemporaneous genus Bonnerichthys. Rhinconichthys is a smaller form (adult lengths around $2-3 \mathrm{~m}$ ), has a fully ossified and tightly sutured skull roof (with the exception of parietal-postparietal midline), and a more gracile skull construction with elongate hyomandibulae lacking an opercular process. Bonnerichthys is a larger form (adult lengths around $5 \mathrm{~m}$ ), lacks sutures between thickened skull roof bones, and has relatively short and robust hyomandibulae with a prominent opercular process. Therefore, suspension-feeding strategies of these late Cretaceous pachycormids is likely to be as different as their skull construction.

The geologically oldest known specimen of Bonnerichthys (KUVP 49505) was recovered from just below the Coniacian-Santonian boundary ( $~ 87 \mathrm{Ma})$. Rhinconichthys purgatoirensis sp. nov. (DMNH 63794) is the geologically youngest occurrence of the genus Rhinconichthys ( $92 \mathrm{Ma})$. Thus from the limited evidence available, Rhinconichthys predates Bonnerichthys by about 5 million years. Evidence for Rhinconichthys is quite limited (three specimens); however all occurrences are from widely separated parts of the globe. Occurrences of Bonnerichthys, though more numerous, are geographically constrained to only North America, specifically the United States. Whether or not these constraints of chronology or geography hold any meaning requires more evidence.

Broader consideration of animals occupying the Mesozoic large suspension-feeding vertebrate niche, including Cretaceous sharks (Shimada et al., 2015) and the Jurassic pachycormids Martillichthys, Asthenocormus, and Leedsichthys (Liston, 2008, 2013), demonstrates the wide diversity of marine suspensionfeeding fishes present throughout the latter half of the Mesozoic. Of the aforementioned forms, the skull construction of Rhinconichthys and Martillichthys is strikingly similar, though temporally separated by some 75 million years. The skull roof of Martillichthys is more elongate than Rhinconichthys, evident from the larger and longer postparietals that extend posteriorly to near the occipital condyle. However, both forms possess an elongate cranium with a narrow tapered snout, slender and recurved jaw elements, and a distinct 'under-bite' evidenced by the gap between the rostrodermethmoid and lower jaws in occlusion. The 'under-bite' is a characteristic unique within pachycormids as noted by Liston (2008). A previously mentioned Turonian suspension-feeding pachycormid from the Vallecillo quarry in Mexico (Blanco-Piñón et al., 2002) also seems highly similar to Rhinconichthys.

\section{Phylogenetic analysis}

Testing the phylogenetic relationships amongst the three Rhinconichthys species and other suspension-feeding pachycormids is complicated by a number of factors. Foremost among limitations is the near complete lack of postcranial information. With the exception of $R$. purgatoirensis sp. nov., the only other known Rhinconichthys skulls are incomplete. Derived members of suspension feeding pachycormids are edentulous (Asthenocormus, Bonnerichthys, Leedsichthys, Martillichthys, and Rhinconichthys), thus the suite of dentition and tooth characters used to assess a broader group of teleosts are uninformative. Simply scoring the edentulous nature of jaws complicates systematic testing, as the toothless condition is effectively a single state but can be scored for multiple bony elements, and because the edentulous condition is subject to homoplasy.

Nevertheless, we conducted a new phylogenetic analysis using the data matrix of Friedman (2012) that consists of 121 characters and 29 taxa. We reduced this matrix to 28 taxa by omitting Hypsocormus macrodon, as the taxonomic placement of this taxon is controversial (Lambers, 1992). We note that our data matrix was calculated both with and without inclusion of ' $H$.' macrodon, and the resultant topology of the cladogram was unchanged. We rescored several characters for Rhinconichthys based upon new information herein (see Appendix, in Supplemntary material). We modified Character 32 of Friedman (2012), adding a third character state to link the synapomorphic condition of dentaries extending beyond the rostrodermethmoid in Martillichthys and Rhinconichthys. Additionally, we added four new characters for a total of 125 (see Appendix), focusing on attributes that may serve to distinguish amongst suspension-feeding pachycormids (bowed dentaries, edentulous condition, suturing of skull roof, and opercular process of hyomandibular).

Our employment of the data matrix utilized PAUP*4.0b10 for Windows (Swofford, 2002). A strict consensus tree (Fig. 10) using the same search parameters as Friedman (2012) is well resolved within suspension feeding pachycormids prior to any refined analysis, and statistics are nearly identical to the original matrix although 11 steps longer (tree length, 234; consistency index, 0.55; rescaled consistency index, 0.42 ; retention index, 0.77 ). The original matrix produced three most parsimonious trees, the unresolved portion occurring among suspension feeding pachycormids with a polytomy of 'Asthenocormus + Leedsichthys + Martillichthys'. The modified dataset produced a single most parsimonious tree (Fig. 10), although we note that the result within suspension feeding pachycormids differs from biostratigraphic chronology. Appearance of the various suspension feeding pachycormid genera in the stratigraphic record suggests that Asthenocormus, Leedsichthys, and Martillichthys should be basal members of the suspension feeding pachycormid clade. We anticipated branching within suspension feeding pachycormids, but chronology suggests Rhinconichthys should not be the basal member of this clade. The tree is stable in uniting suspension-feeding pachycormids. However, elimination or inclusion/exclusion of single characters or character states can markedly change branching within the group. We include our test to further support the monophyly of suspension feeding pachycormids, and to demonstrate 


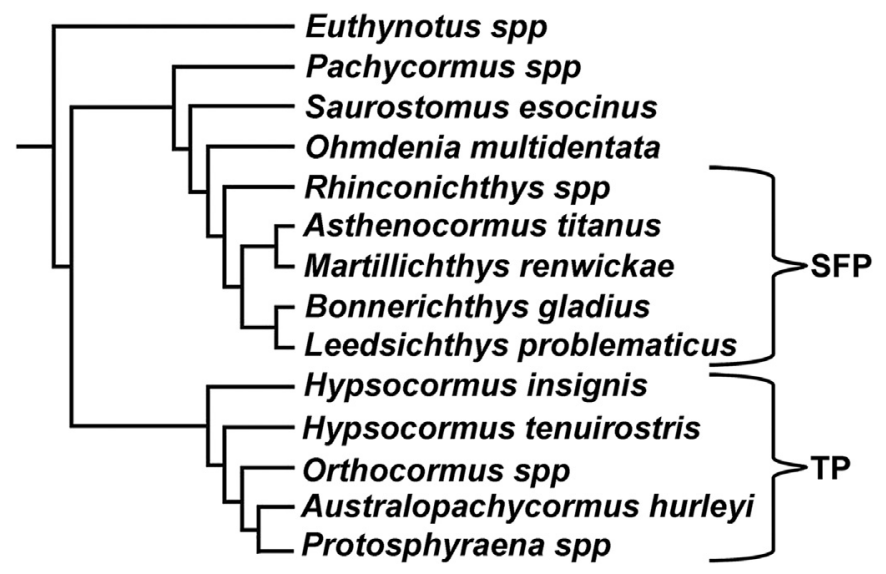

Fig. 10. Consensus tree (one most parsimonious tree) derived from data matrix of Friedman (2012), with modifications as shown in Appendix. 'SFP' denotes suspensionfeeding pachycormids; 'TP' denotes toothed pachycormids.

that resolution within the group will require further testing using a broader dataset and/or more information from new fossils. In particular, resolution within Rhinconichthys will require more postcranial information.

Our phylogenetic analysis scored Rhinconichthys species as a single taxon due to severe limitations of material and incomplete skulls of $R$. taylori and $R$. uyenoi sp. nov.. From a chronological standpoint, $R$. taylori (NHMUK PV OR 33219) and $R$. uyenoi sp. nov. (NSM VP21868) are Cenomanian in age (Friedman et al., 2010) and thus older than $R$. purgatoirensis sp. nov. (DMNH 63794). When the preserved portions of the cranial roofs among the three species are compared, the basic architecture of postparietals and how they articulate with parietals anteriorly and dermopterotics laterally are similar between $R$. uyenoi sp. nov. and $R$. purgatoirensis sp. nov., and markedly differ from $R$. taylori (see Fig. 8). In addition, the straight-edged hyomandibula outlines of $R$. uyenoi sp. nov. and $R$. purgatoirensis sp. nov. contrast with the sinusoidal hyomandibula outline of $R$. taylori (Fig. 8). Therefore, we propose the following working hypothesis about the phylogenetic relationships of the three Rhinconichthys species: $[R$. taylori [R. uyenoi sp. nov. $+R$. purgatoirensis sp. nov.]].

\section{Conclusions}

The new specimen DMNH 63794 is here referred to Rhinconichthys. Known specimens of Rhinconichthys represent three distinct species: $R$. taylori, $R$. purgatoirensis sp. nov., and $R$. uyenoi $\mathrm{sp}$. nov. With only three known specimens, Rhinconichthys remains a poorly known clade of suspension-feeding pachycormids. Rhinconichthys purgatoirensis sp. nov. is the sole record of the genus from the Western Hemisphere, and extends the temporal range to the middle Turonian (ammonite zone of Collignoniceras woollgari). Together with Bonnerichthys (Friedman et al., 2013) and a putative Cenomanian-Turonian planktivorous shark clade from the USA and Russia (Shimada et al., 2015), R. purgatoirensis sp. nov. demonstrates that a diversity of suspension-feeding fishes was present in the world's oceans throughout the Late Cretaceous.

Rhinconichthys is likely an obligate suspension feeder based upon the unusual skull construction, large gill basket, and exceptionally large and elongate hyomandibula independent from the opercular series. The hyomandibula acts as an elongate lever, allowing greatly amplified protrusion of the jaws and expansion of the buccal cavity. This specialized cranial construction was previously unknown among Cretaceous bony fish, and functionally parallels that of the modern paddlefish Polyodon and many sharks. The presence of an elongate supramaxilla bordering the dorsal rim of the maxilla is also novel among pachycormids.

The total length of $R$. purgatoirensis sp. nov. is estimated to be between 2.0 and $2.7 \mathrm{~m}$ based upon comparison with two Jurassic pachycormid genera which possess markedly different body proportions, Martillichthys and Asthenocormus. The size range of the three known skulls of Rhinconichthys suggests that adult size of the genus is modest in comparison to Bonnerichthys. Size difference, as well as markedly different skull architecture, suggest distinctly different suspension-feeding strategies for these genera. Discoveries like that of DMNH 63794 are rapidly changing historical views of planktivory in the Earth's oceans.

\section{Acknowledgements}

The authors thank Kevin Lindahl for his assistance and enthusiasm in the field which led to the fortuitous discovery of DMNH 63794. The Arkansas Valley Regional Medical Center (La Junta, Colorado, USA) provided CT and x-ray images of the specimen. Mike Triebold of the Rocky Mountain Dinosaur Resource Center (Woodland Park, Colorado, USA) donated time and materials to replicate the specimen. Matt Friedman (Oxford University, UK) provided valuable advice on initial assessment of the specimen. Soledad Gouiric Cavalli also provided helpful discussion on vertebral centra development. Charlie Underwood provided constructive discussion on planktivore vertical migration. Access to NHMUK collections and photography was kindly provided by Emma Bernard. Makoto Manabe, Naoki Kohno, and Chisako Sakata (NSM) kindly provided photographs of NSM VP21868. Assistance from two anonymous reviewers and Eduardo KoutSoukos (editor) greatly improved the final version of this manuscript.

\section{References}

Arratia, G., 2013. Morphology, taxonomy, and phylogeny of Triassic pholidophorid fishes (Actinopterygii, Teleostei). Journal of Vertebrate Paleontology Memoir 13, $1-138$.

Arratia, G., Schultze, H.P., 2013. Outstanding features of a new Late Jurassic pachycormiform fish from the Kimmeridgian of Brunn, Bermany and comments on current understanding of pachycormiforms. In: Arratia, G., Schultze, H.-P., Wilson, M.V.H. (Eds.), Mesozoic Fishes 5-Global Diversity and Evolution. Verlag Dr. Freidrich Pfeil, München, Germany, pp. 87-120.

Berg, L.S., 1937. A classification of fish-like vertebrates. Bulletin de l'Académie des Sciences de l'U.R.S.S. Classe des Sciences mathématiqueset naturelles 4, 1277-1280.

Blanco-Piñón, A., Frey, E., Stinnesbeck, W., Lopez Oliva, J.G., 2002. Late Cretaceous (Turonian) fish assemblage from Vallecillo, northeastern Mexico. Neues Jahrbuch für Geologie und Paläontologie, Abhandlungen 225, 39-54.

Bowen, S.H., 1983. Detritivory in neotropical fish communities. Environmental Biology of Fishes 9, 137-144.

Burggren, W.W., Bemis, W.E., 1992. Metabolism and ram gill ventilation in juvenile paddlefish, Polyodon spathula (Chondrostei: Polyodontidae). Physical Zoology 65, 515-539.

Carroll, A.M., Wainwright, P.C., 2003. Functional morphology of prey capture in the sturgeon, Scaphirhynchus albus. Journal of Morphology 256, 270-284.

Cobban, W.A., Scott, G.R., 1972. Stratigraphy and ammonite fauna of the Graneros Shale and Greenhorn Limestone near Pueblo, Colorado. United States Geological Survey Professional Paper 645, pp. 1-108.

Freedman, J.A., Noakes, D.L.G., 2002. Why are there no really big bony fishes? A point-of-view on maximum body size in teleosts and elasmobranchs. Reviews in Fish Biology and Fisheries 12, 403-416.

Friedman, M., 2012. Parallel evolutionary trajectories underlie the origin of giant suspension-feeding whales and bony fishes. Proceedings of the Royal Society Bulletin 279, 944-951.

Friedman, M., Shimada, K., Martin, L.D., Everhart, M.J., Liston, J., Maltese, A., Triebold, M., 2010. 100-million-year dynasty of giant planktivorous bony fishes in the Mesozoic seas. Science 327, 990-993.

Friedman, M., Shimada, K., Everhart, M.J., Irwin, K.J., Grandstaff, B.S., Stewart, J.D., 2013. Geographic and stratigraphic distribution of the late Cretaceous suspension-feeding bony fish Bonnerichthys gladius (Teleostei, Pachycormiformes). Journal of Vertebrate Paleontology 33,1-13.

Grande, L., Bemis, W.E., 1991. Osteology and phylogenetic relationships of fossil and recent paddlefishes (Polyodontidae) with comment on the 
interrelationships of Acipenseriformes. Journal of Vertebrate Paleontology Memoir 1, 1-121.

Hattin, D.E., 1975. Stratigraphy and depositional environment of the Greenhorn Limestone (Upper Cretaceous) of Kansas. Kansas Geological Survey Bulletin 209 $1-128$.

Hay, O.P., 1903. On certain genera and species of North American Cretaceous actinopterous fishes. American Museum of Natural History Bulletin 19, $1-95$.

Huxley, T.H., 1880. On the application of the laws of evolution to the arrangement of the Vertebrata, and more particularly of the Mammalia. Proceedings of the Zoological Society, London 43, 649-662.

Kear, B.P., 2007. First record of a pachycormid fish (Actinopterygii: Pachycormiformes) from the lower Cretaceous of Australia. Journal of Vertebrate Paleontology 27 (4), 1033-1038.

Kennedy, W.J., Walaszczyk, I., Cobban, W.A., 2005. The global boundary stratotype section and point for the base of the Turonian Stage of the Cretaceous: Pueblo, Colorado, U.S.A. Episodes 28, 93-104.

Lambers, P.H., 1992. On the Ichthyofauna of the Solnhofen Lithographic Limestone (Upper Jurassic, Germany). PhD thesis. Rijksuniversiteit Groningen, Groningen, The Netherlands, 336 p.

Lazzaro, X., 1987. A review of planktivorous fishes: their evolution, feeding behaviours, selectivities, and impacts. Hydrobiologia 146, 97-167.

Liston, J., 2008. A review of the characters of the edentulous pachycormiforms Leedsichthys, Asthenocormus and Martillichthys nov. gen. In: Arratia, G., Schultze, H.-P., Wilson, M.V.H. (Eds.), Mesozoic Fishes 4-Homology and Phylogeny. Verlag Dr. Freidrich Pfeil, München, Germany, pp. 181-198.

Liston, J.J., 2013. The plasticity of gill raker characteristics in suspension feeders: implications for Pachycormiformes. In: Arratia, G., Schultze, H.-P. Wilson, M.V.H. (Eds.), Mesozoic Fishes 5-Global Diversity and Evolution. Verlag Dr. Freidrich Pfeil, München, Germany, pp. 121-143.

Liston, J., Friedman, M., 2012. The world's first clade of giant marine suspensionfeeders: a palaeobiogeographical review of the Pachycormiformes. Ameghiniana 48 (4), R236.

Liston, J.J., Newbrey, M.G., Challands, T.J., Adams, C.E., 2013. Growth, age and size of the Jurassic pachycormid Leedsichthys problematicus (Osteichthyes: Actinopterygii). In: Arratia, G., Schultze, H.-P., Wilson, M.V.H. (Eds.), Mesozoic Fishes 5-Global Diversity and Evolution. Verlag Dr. Freidrich Pfeil, München, Germany, pp. 145-175.

Loomis, F.B., 1900. Die Anatomie und die Verwandtschaft der Ganoid- und Knochen-Fischeaus der Kreide Formation von Kansas. Palaeontographica 46, 213-283.

Mainwaring, A.J., 1978. Anatomical and Systematic Review of the Pachycormidae, a Family of Mesozoic Fossil Fishes (Ph.D. thesis). Westfield College, University of London, pp. 1-62p.

Maltese, A., Liston, J.J., 2014. Daggers, swords, scythes and sickles: pachycormid fins as ecological predictors. In: Society of Vertebrate Paleontology Meeting, Berlin, Germany, p. 176 abstracts.
Motta, P.J., 2004. Prey capture behavior and feeding mechanics of elasmobranchs. In: Carrier, J., Musick, J., Heithaus, M. (Eds.), Biology of Sharks and Their Relatives. CRC Press, Boca Raton, FL, USA, pp. 165-202.

Motta, P.J., Huber, D.R., 2012. Prey capture behavior and feeding mechanics of elasmobranchs. In: Carrier, J.C., Musick, J.A., Heithaus, M.R. (Eds.), Biology of Sharks and Their Relatives, Second ed. CRC Press, Boca Raton, FL, USA, pp. 153-209.

Sanderson, S.L., Wassersug, R., 1993. Convergent and alternative designs for vertebrate suspension feeding. In: Hanken, J., Hall, B.K. (Eds.), The Skull, Volume 3: Functional and Evolutionary Mechanisms. Chicago University Press, Chicago, pp. 37-112.

Schumacher, B.A., Maltese, A., 2013. When Plankton ruled the Comanche National Grassland, discovery of a third North American Cretaceous filter-feeding vertebrate. In: Society of Vertebrate Paleontology Meeting, Los Angeles, CA abstract.

Shimada, K., Popov, E.V., Siversson, M., Welton, B.J., Long, D.J., 2015. A new clade of putative plankton-feeding sharks from the Upper Cretaceous of Russia and the United States. Journal of Vertebrate Paleontology 35 (5), e981335. http:// dx.doi.org/10.1080/02724634.2015.981335.

Stewart, J.D., 1988. Stratigraphic distribution of Late Cretaceous Protosphyraena in Kansas and Alabama. Fort Hays State University Studies 3, 80-94.

Swofford, D., 2002. PAUP*: Phylogenetic analysis using parsimony (* and other methods). Version 4.0b10. Sinauer Associates, Sunderland, Massachusetts.

van den Berg, C., van Snik, G.J.M., van den Boogaart, J.G.M., Sibbing, F.A., Osse, J.W.M., 1994. Comparative microanatomy of the branchial sieve in three sympatric cyprinid species, related to filter-feeding mechanisms. Journal of Morphology 219, 73-87.

Westneat, M.W., 1995. Phylogenetic systematics and biomechanics in ecomorphology. Environmental Biology of Fishes 44, 263-283.

Westneat, M.W., 2004. Evolution of levers and linkages in the feeding mechanisms of fishes. Integrative Comparative Biology 44, 378-389.

Westoll, T.S., 1943. The origin of the tetrapods. Biological Reviews 18, 78-98.

Woodward, A.S., 1891. Catalogue of Fossil Fishes in the British Museum (Natural History), Part II. Trustees of the British Museum (Natural History), London, pp. $1-567$.

Woodward, A.S., 1895. Catalogue of Fossil Fishes in the British Museum (Natural History), Part III. Trustees of the British Museum (Natural History), London, pp. 1-544.

\section{Appendix A. Supplementary data}

Supplementary data related to this article can be found at http://dx.doi.org/10. 1016/j.cretres.2015.12.017 